\title{
Late-onset localized junctional epidermolysis bullosa-intellectual disability syndrome
}

INSERM

\section{Source}

INSERM. (1999). Orphanet: an online rare disease and orphan drug data base. Late-onset localized junctional epidermolysis bullosa-intellectual disability syndrome. ORPHA:231556

Late-onset localized jonctional epidermolysis bullosa-intellectual disability syndrome is a rare junctional epidermolysis bullosa subtype characterized by late-onset blistering surrounded by erythema and localized on the anterior aspect of the lower legs, associated with dystrophic toenails, tooth enamel defects and mild to severe intellectual disability. Lens subluxation and mild facial dysmorphism (with short midface, prognatism and thin upper lip vermilion) are additional reported features. There have been no further descriptions in the literature since 1992. 